\title{
Pengembangan Sistem Informasi Pemantauan Alat Kesehatan Untuk Mendukung Penjaminan Mutu Pelayanan Kesehatan Di Balai Kesehatan Indera Masyarakat (BKIM) Provinsi Jawa Tengah
}

\author{
Hamdan Syah Alam ${ }^{1}$, Sudiro ${ }^{2}$, Cahya Tri Purnami ${ }^{2}$ \\ 1) Balai Kesehatan Indera Masyarakat (BKIM) Provinsi Jawa Tengah, Semarang \\ $\left.{ }^{2}\right)$ Fakultas Kesehatan Masyarakat, Universitas Diponegoro, Semarang
}

Title : System Information Development on Monitoring Activities of the Medical Device to Support the Quality Assurance of Health Services in Central Java Sense Organs Health Center (SOHC)

\begin{abstract}
Abstrak
Kegiatan pemantauan alat kesehatan di Balai Kesehatan Indera Masyarakat (BKIM) Provinsi Jawa Tengah masih sangat sederhana. Pemantauan hanya dilakukan jika ada usulan perbaikan dari ruangan pelayanan kesehatan. Sulit untuk mengetahui keberadaan dan kondisi alat kesehatan yang ada di seluruh ruangan pelayanan. Beberapa masalah yang ada pada sistem informasi pemantauan alat kesehatan yang ada saat ini antara lain pembantu petugas barang sulit melakukan pemantauan terhadap alat yang rusak, dipinjam atau yang dihapus. Manajemen juga sulit melakukan pemantauan alat kesehatan di seluruh ruangan karena tidak tersedianya informasi yang lengkap, sesuai, akurat dan pelaporan yang tidak tepat waktu. Tujuan penelitian ini adalah melakukan pengembangan sistem informasi pemantauan alat kesehatan untuk mendukung penjaminan mutu pelayanan kesehatan di BKIM Provinsi Jawa Tengah.

Jenis penelitian yang digunakan adalah kualitatif dan kuantitatif. Desain penelitian ini adalah desain Pre Experimental dengan pendekatan one group pretes-posttes, pengembangan sistem menggunakan metode FAST (framework for the Application of system Techniques). Subjek penelitian terdiri dari Kepala BKIM, Kepala Sub Bagian Tata Usaha, Kepala Seksi Pengobatan dan Perawatan, Pembantu Pengurusan Barang, Kepala Ruangan dan Penanggungjawab Barang Ruangan responden yang berasal dari BKIM Provinsi Jawa Tengah. Hasil observasi dan wawancara dilakukan dengan metode analis isi dan analisis deskriptif dengan menggunakan rata-rata tertimbang. Hasil analisis data secara deskriptif menunjukkan
\end{abstract}

bahwa nilai rata-rata tertimbang secara keseluruhan kualitas infromasi sebelum pengembangan sistem 37,73 dan setelah pengembangan sistem 78,90 dengan selisih 41,17. Perlu adanya komitmen dan dukungan dari pimpinan BKIM Provinsi Jawa Tengah serta memonitor secara berkelanjutan terhadap implementasi sistem informasi pemantauan alat kesehatan yang sudah dikembangkan secara optimal. Sosialisasi dan pelatihan kepada semua personil yang mempunyai tugas pokok dan fungsi dalam bekerja yang berkaitan dengan alat kesehatan. Tersedianya anggaran untuk biaya operasional dan perawatan sistem.

$\begin{array}{ll} & \text { Kata kunci : Sistem Informasi, } \\ & \text { Pemantauan, Alat Kesehatan, } \\ & \text { Pelayanan Kesehatan } \\ \text { Referensi } \quad \text { : Jumlah } 7(1991-2015)\end{array}$

\begin{abstract}
Monitoring activities of the medical device in Central Java Sense Organs Health Center (SOHC) is still very simple. It is only done if there is a report or proposed reparation service from the health care rooms. It is difficult to know the whereabouts and condition of medical devices in the entire service rooms. Some of the problems that exist in the monitoring of medical devices information system that is available today are manager encounters difficulty to monitor the condition of the devices, whether they are broken, borrowed or deleted. Managers are also difficult to monitor the medical devices throughout the rooms because of the unavailability of complete, appropriate, and accurate information. Moreover, there is no on time regular report for those conditions. The purpose of this study was to develop a health information system monitoring tools to support the quality assurance of health
\end{abstract}


services in Central Java Sense Organs Health Center (SOHC).

The type of this research is qualitative and quantitative with Pre Experimental design approach of one pre-test and post-test group. The development of the system used FAST (Framework for the Application of the system Techniques) method. Where as the subjects consisted of the head of SOHC, the head of administrative department, the head of healing and treatment section, the head of promotion, prevention and rehabilitation section, devices manager assistant, the head of room, and domestic devices care-taker respondents of SOHC from Central Java. Observations and interviews are conducted with the contents and descriptive analysis method using a weighted average. The results shows that the weighted average value of the overall information quality of before the development of the system is 37,73 and after the development of the system is 78,90 with a difference 41,17 points.

It is important for the leader of SOHC to increase the commitment and support on monitoring the implementation of medical device monitoring information system that has been optimally developed. Moreover, they need to socialize and train all personnel who have responsibility related to medical devices. The last, it is also urgent to make availability of the budget for operational costs and system maintenance.

\section{Keywords \\ Information Systems, Monitoring, Medical Devices, Health Services Bibliography : 61 (1991-2015)}

\section{Pendahuluan}

Balai Kesehatan Indera Masyarakat (BKIM) adalah unit pelaksana teknis Dinas Kesehatan Kabupaten/Kota/Provinsi/Pusat yang menyelenggarakan upaya kesehatan masyarakat (UKM) dan upaya kesehatan perorangan (UKP) strata kedua bidang kesehatan indera penglihatan dan pendengaran di wilayah kerjanya. ${ }^{1}$ BKIM Provinsi Jawa Tengah mempunyai tugaspokok melaksanakan sebagian kegiatan teknis operasional dan atau kegiatan teknis penunjang Dinas Kesehatan di bidang kesehatan indera masyarakat. BKIM mempunyai fungsi menyusun rencana teknis dan melaksanakan operasional bidang promosi, pencegahan dan rehabilitasi, diagnosa, pengobatan dan perawatan indera masyarakat, serta melakukan pemantauan, evaluasi, pelaporan bidang kesehatan indera masyarakat. $^{2}$

Pelayanan kesehatan yang diselenggarakan di BKIM Provinsi Jawa Tengah adalah spesialistik mata, spesialistik telinga, hidung dan tenggorokan, spesialistik kulit dan kelamin, kesehatan gigi dan mulut, pemeriksaan laboratorium dan pelayanan kefarmasian, yang dalam penyelenggaraan pelayanan kesehatan dilengkapi dengan sarana dan prasarana yang memadai seperti alat-alat kesehatan sesuai dengan jenis pelayanan kesehatan yang diberikan. Agar alat-alat kesehatan tersebut mendukung mutu pelayanan kesehatan, maka perlu dilakukan pemantauan. Yaitu pemantauan terhadap alatalat kesehatan yang bermasalah seperti alat yang rusak, tidak dikalibrasi, alat yang dipinjam, alat yang diusulkan untuk diperbaiki maupun alat yang dihapus.

Kegiatan pemantauan alat kecohoton seharusnya memiliki karakteristik 1 berikut. ${ }^{3}$

1. Terencana, sistematis, mencakup semua aspek-aspek penting layanan kesehatan, dilakukan secara berkesinambungan dan menyeluruh. Hal ini agar program pemantauan alat kesehatan dapat terlaksana sesuai dengan harapan untuk memastikan terwujudnya peningkatan mutu layanan kesehatan.

2. Melibatkan pengumpulan dan rutin yang terkait dengan indikator. Hal ini agar pantauan memberikan hasil secara menyeluruh dan mencakup semua indikator pemantauan seperti gangguan, kerusakan, kalibrasi, perbaikan dan penghapusan.

3. Pemantauan harus terpadu, informasi yang diperoleh disebarluaskan kepada satuan kerja atau fasilitas layanan kesehatan lain. Hal ini agar pelaksanaan pemantauan lebih efisien dan efektif.

Semua alat kesehatan yang ada didata sesuai dengan spesifikasi alat dan ruangan di mana alat tersebut ditempatkan. Pendataan alat kesehatan di BKIM telah menggunakan sebuah sistem informasi aset yang berorientasi pada persediaan (inventory). Sistem informasi aset yang ada saat ini 
menghasilkan informasi tentang persediaan barang di masing-masing ruangan. Sistem ini tidak dapat memberikan informasi tentang kondisi alat-alat kesehatan yang ada di semua ruangan. Output yang dihasilkan tidak dapat digunakan untuk melakukan pemantauan kondisi alat kesehatan yang ada, serta membuat manajemen sulit untuk melakukan pemantauan alat kesehatan.

Alat-alat kesehatan yang digunakan harus dalam pemantauan untuk menjamin bahwa alat tersebut memenuhi persyaratan mutu, keamanan, dan kemanfaatan. Alat kesehatan yang digunakan harus benar-benar berfungsi dengan baik, sesuai dengan amanat Permenkes No. 1184/Menkes/Per/X/ 2004 Pasal 69 ayat 1 yang menyatakan bahwa dalam rangka menjamin alat kesehatan dan perbekalan kesehatan yang memenuhi persyaratan mutu, keamanan, dan kemanfaatan diselenggarakan upaya pemeliharaan mutu alat kesehatan dan perbekalan kesehatan. ${ }^{4}$ Setiap alat kesehatan wajib dilakukan pengujian dan atau kalibrasi untuk menjamin kebenaran nilai keluaran atau kinerja dan keselamatan pemakaian sesuai dengan pasal 2 ayat 1 Permenkes Nomor 363/MENKES/PER/IV/1998., 5

Kepala Sub Bagian Tata Usaha BKIM Provinsi Jawa Tengah menjelaskan bahwa pemantauan alat kesehatan di BKIM Provinsi Jawa Tengah dikelola oleh Sub Bagian Tata Usaha. Kegiatan pemantauan alat kesehatan dilakukan masih sangat sederhana. Pemantauan alat kesehatan hanya dilakukan jika ada laporan atau usulan perbaikan dari ruangan pelayanan sebagai dasar untuk melakukan pemeliharaan atau perbaikan alat kesehatan. Sulit untuk mengetahui keberadaan dan kondisi alat kesehatan yang ada di seluruh ruangan pelayanan. Tidak ada dilakukan pemantauan alat kesehatan jika tidak ada laporan atau usulan dari ruangan pelayanan. Alat-alat kesehatan yang ada diseluruh ruangan pelayanan tidak terpantau dengan baik apakah kondisinya rusak, harus dikalibrasi atau harus diganti, yang membuat tidak ada jaminan memenuhi persyaratan mutu, keamanan, maupun kemanfaatan dan berdampak tidak baik pada mutu pelayanan kesehatan.
Kegiatan pemantauan alat kesehatan di BKIM Provinsi Jawa Tengah belum dilakukan secara rutin karena belum ada tenaga teknis alat kesehatan. Yang dilakukan adalah kalibrasi terhadap alat-alat elektromedik setiap setahun sekali oleh pihak ketiga.

Melakukan inventarisasi alat kesehatan yang berkaitan dengan pendataan aset milik BKIM Provinsi Jawa Tengah. Hal tersebut belum efektif dalam memantau keberadaan dan kondisi alat kesehatan yang ada di semua ruangan pelayanan kesehatan dan alat kesehatan yang dipinjam oleh ruangan lain. Karena dari kegiatan yang dilakukan tersebut belum mampu memberikan informasi yang akurat dan lengkap sesuai dengan yang dibutuhkan oleh manajemen untuk melakukan pemantauan alat kesehatan di seluruh ruangan pelayanan kesehatan.

Hasil penelitian Janahar Murad (1991) tentang Sistem Monitoring Efek Pengamanan Alat Kesehatan menjelaskan bahwa alat kesehatan yang bermasalah 63 persen, sedangkan alat kesehatan yang rusak 10 persen. Peralatan kesehatan yang seringkali mengalami kerusakan misalnya tensimeter sering macet waktu dipakai, akibatnya hasil yang didapat tidak tepat sehingga mempengaruhi pemberian obat. Alat bedah listrik kadang-kadang menyebabkan kulit terbakar waktu digunakan selama operasi. Alarm dan signal pada alat bantu pernafasan terganggu akibat perubahan tegangan. ${ }^{6}$

I Nengah Kuning Atmadjaya (2015), sebagai Direktur Medik dan Keperawatan RSUP Sanglah Bali menjelaskan bahwa setelah dilakukan pemeriksaan terhadap alat-alat kesehatan, ternyata banyak alat yang rusak dan langkah awal yang dilakukan adalah melakukan pendataan alat-alat kesehatan yang rusak. $^{7}$ Hal ini membuktikan bahwa dengan tidak dilakukan pemantauan alat kesehatan berakibat banyaknya alat kesehatan yang rusak dan serta tidak terpantau dan membutuhkan biaya yang sangat besar untuk memperbaikinya.

Dengan pertimbangan tingginya persentase alat kesehatan yang bermasalah dan apa yang terjadi di RSUP Sanglah Bali tersebut, maka selayaknya BKIM Provinsi Jawa Tengah mengembangkan sistem informasi 
pemantauan alat kesehatan yang dapat memberikan informasi yang dibutuhkan oleh manajemen dalam pemantauan alat kesehatan. Dengan sistem informasi ini manajemen mudah melakukan pemantauan terhadap alatalat kesehatan di semua ruangan pelayanan kesehatan dan sebagai dasar untuk pemeliharaan, kalibrasi dan perbaikan terhadap alat kesehatan yang bermasalah atau rusak.

\section{Metode Penelitian}

Jenis penelitian yang digunakan adalah penelitian pre eksperimental one group pretest post-test kualitatif dan kuantitatif. Pada awal penelitian dilakukan wawancara mendalam dengan pengguna sistem atau responden dan observasi untuk mengidentifikasi masalah dan mengukur kualitas informasi secara kualitatif pada sistem yang lama. Selain dengan wawancara mendalam, dilakukan juga pengukuran informasi sistem yang lama dengan membagikan lembar kuesioner kepada para responden. Jawaban dari wawancara mendalam dengan para responden merupakan data pre-test kualitatif dan digunakan untuk mengukur kualitas informasi kualitatif dan mendukung pengukuran kualitas informasi kuantitatif. Jawaban responden atas lembar kuesioner yang diberikan merupakan data pre-test kuantitatif dan digunakan untuk mengukur kualitas informasi kuantitatif.

Subyek penelitian adalah semua orang yang tupoksinya berhubungan dengan alat kesehatan yang ada di BKIM Provinsi Jawa Tengah sebanyak 18 orang yang terdiri dari Kepala BKIM 1 orang, Kepala Sub Bagian Tata Usaha 1 orang, Kepala Seksi Pengobatan dan Perawatan 1 orang, Pembantu Pengurus Barang 1 orang dan Penanggungjawab Barang Ruangan 14 orang. ${ }^{2}$ Data yang diambil dalam penelitian ini adalah data primer melalui wawancara mendalam dan data sekunder melalui observasi. Setelah pengumpulan data selesai dilaksanakan maka data dianalisis menggunakan metode analisis isi dan analisis deskriptif.

\section{Hasil}

Karakteristik Responden

Tabel 1 Latar Belakang Pendidikan Responden

\begin{tabular}{|c|c|c|c|c|c|c|}
\hline \multirow{2}{*}{ No. } & \multirow{2}{*}{ Responden } & \multicolumn{5}{|c|}{ Latar Belakang Pendidikan } \\
\hline & & SMA & D3 & D4 & S1 & $\mathrm{S} 2$ \\
\hline $\mathrm{R} 1$ & Kepala BKIM & & & & & 1 \\
\hline $\mathrm{R} 2$ & Kepala Sub Bagian Tata Usaha & & & & & 1 \\
\hline R3 & Kepala Seksi Pengobatan dan Perawatan & & & & 1 & \\
\hline $\mathrm{R} 4$ & Pembantu Pengurus Barang & 1 & & & & \\
\hline R5 & Penanggungjawab Barang Ruangan & 6 & 2 & & 6 & \\
\hline
\end{tabular}

Berdasarkan tabel 1 diperoleh informasi bahwa responden yang memiliki latar belakang pendidikan SMA ada 7 orang, latar belakang pendidikan D3 ada 2 orang, latar belakang pendidikan S1 ada 7 orang dan latar belakang pendidikan S2 ada 2 orang.

Gambaran Umum dan Permasalahan Sistem Informasi Pemantauan Alat Kesehatan

Sistem informasi pemantauan alat kesehatan masih dilakukan dengan sederhana. Pemantauan alat kesehatan dilakukan hanya jika ada usulan perbaikan dari ruangan pelayanan. Penyelenggraan pemeliharaan dan perbaikan alat kesehatan di BKIM Provinsi Jawa Tengah dimulai dari Penggungjawab
Barang Ruangan mencatat alat yang rusak atau bermasalah di formulir laporan kerusakan barang dan diusulkan atau dilaporkan kepada Kepala Seksi Pengobatan dan Perawatan dan dilanjutkan kepada Pembantu Pengurus Barang. Berdasarkan usulan atau laporan tersebut Pembantu Pengurus Barang menindaklanjuti dengan mengecek ulang atau verifiksi kondisi alat yang dilaporkan. Hasil verifikasi alat dilaporkan kepada Kepala Sub Bagian Tata Usaha untuk dilakukan perbaikan. Atas dasar persetujuan dari Kepala Sub Bagian Tata Usaha dilakukan perbaikan alat kesehatan. 
Sistem informasi pemantauan alat kesehatan di BKIM Provinsi Jawa Tengah belum dapat memberikan informasi yang dibutuhkan untuk melakukan pemantauan alat kesehatan seperti informasi alat yang rusak, tidak dikalibrasi, dipinjam oleh ruangan lain dan sebagainya. Sistem informasi yang ada tidak dapat menyediakan informasi kondisi alat kesehatan secara lengkap, sesuai, akurat dan tepat waktu. Akibatnya kondisi alat kesehatan di BKIM Provinsi Jawa Tengah belum terpantau dengan baik oleh manajemen. Jika kondisi alat-alat kesehatan di BKIM Provinsi Jawa Tengah belum dapat dipantau dengan baik, maka tidak ada jaminan bahwa alat-alat kesehatan tersebut memenuhi persyaratan mutu, keamanan dan kemanfaatan. Hal tersebut menjadi masalah dalam penjaminan mutu pelayanan kesehatan di BKIM Provinsi Jawa Tengah.

Sistem Informasi Pemantauan Alat Kesehatan yang Dikembangkan
Pengembangan sistem informasi pemantauan alat kesehatan di BKIM Provinsi Jawa Tengah adalah pengembangan sistem berdasarkan identifikasi masalah, analisis masalah dan analisis persyaratan, serta mempertimbangkan kebutuhan BKIM Provinsi Jawa Tengah. Sistem yang dikembangkan adalah sistem informasi berbasis LAN dan menggunakan basis data yang terintegrasi. Sistem yang dikembangkan menyediakan akses kepada pengguna dan memberikan wewenang kepada pengguna sesuai dengan tingkatan manajemen dan tupoksi. Sistem informasi yang dikembangkan dapat menyediakan informasi yang akurat, lengkap dan tepat waktu sesuai dengan kebutuhan bagi manjemen dalam melakukan pemantauan alat kesehatan di semua ruangan pelayanan kesehatan.

\section{Pembahasan}

Keunggulan dari sistem informasi yang dikembangkan adalah :

1. Memberikan kemudahan akes kepada pengguna yang mendapat hak akses sesuai dengan tupoksi dalam pengelolaan alat kesehatan.

Memberikan kemudahan akses kepada pengguna

R2 : “...Dengan sistem ini saya dengan mudah mengakses informasi alat kesehatan yang saya butuhkan, dan sekarang saya menjadi lebih mudah melakukan pemantauan alat kesehatan...".

R4 : “....Dengan adanya sistem ini saya menjadi terbantu dan lebih mudah mendapatkan informasi yang saya butuhkan. Tidak seperti dulu lagi. Kalo dulu saya kesulitan untuk mendapatkan informasi yang akurat. Karena para penanggungjawab barang ruangan tidak langsung melaporkan ke saya jika ada perubahan data alat kesehatan. Sekarang ini kan mereka dengan mudah melakukan entri data dari ruangan mereka dan saya langsung dapat melihatnya di komputer...".

Penanggungjawab barang Klinik Mata Dasar (R5) :

".... Kalo dulu saya sering menunda-nunda melaporkan perubahan data alat kesehatan ke Pembantu Pengurus Barang. Karena kalo dulu untuk melaporkannya butuh waktu 10 sampai 15 menit, sedangkan saya harus memberikan pelayanan sampai akhir jam pelayanan dan dilanjutkan dengan entri data status pasien. Sekarang ini dengan adanya sistem ini, saya melaporkannya cukup dengan mengentri data ke komputer saja. Menjadi lebih mudah...."

2. Data tersimpan dalam satu basis data yang terintergrasi dan dapat diakses oleh semua pengguna sesuai hak akses yang diberikan.

$$
\text { Data tersimpan dalam satu basis data yang terintergrasi }
$$

R2 : "Kini data tersimpan di server dan kami dapat mengaksesnya dari rungan kerja masing-masing dengan menggunakan aplikasi sistem informasi pemantauan alat kesehatan yang baru ini...”.

R4 : "Sejak menggunakan sistem yang baru ini, data alat kesehatan dan data perbaikan alat kesehatan disimpan di server, dan kami dapat mengaksesnya dari komputer kami yang ada di ruangan kerja kami masing-masing. 
3. Pengguna dapat mengakses sistem informasi dari masing-masing ruangan tempat bekerja. Dapat diakses dari masing-masing ruangan tempat bekerja

R3 : “...Ya, dari ruangan saya sekarang sudah bisa mengakses sistem informasi pemantauan alat kesehatan. Saya dengan mudah memantau alat kesehatan di semua ruangan pelayanan, yang selama ini saya harus ke ruangan-ruangan pelayanan...".

Penanggungjawab barang Klinik Mata Dasar (R5) :

".... Saya senang adanya sistem ini, karena saya bisa melaporkan data alat apatkesehatan kepada Pembantu Pengurus Barang dengan mengaksens sistem dari ruangan kerja saya...."

Penanggungjawab barang Klinik THT Dasar (R5) :

".... Saya sudah bisa mengakses sistem informasi pemantauan alat kesehatan yang baru dari ruangan tempat saya bekerja...."

4. Penanggungjawab Barang Ruangan dapat mengusulkan perbaikan alat kesehatan dengan mudah dari ruangan pelayanan setiap ada alat kesehatan yang bermasalah atau rusak dan manajemen dapat melihat langsung dari komputer usulan dari ruangan pelayanan Usulan dari ruangan pelayanan dapat dilihat langsung dari komputer

R2 : “....Ya, biasanya menunggu laporan usulan yang diberikan oleh Pembantu Pengurus Barang, tetapi dengan adanya sistem yang baru ini saya bisa lihat usulan perbaikan di komputer saya...."

R3 : “...Dengan sistem yang baru saya dapat melihat langsung di komputer saya setiap ada usulan perbaikan alat yang diusulkan dari ruangan pelayanan ...".

5. Pimpinan puncak, menengah dan bawah dengan mudah dapat memantau kondisi alat kesehatan, usulan perbaikan, perbaikan, kalibrasi, peminjaman dan penghapusan alat kesehatan dengan kualitas informasi yang akurat, sesuai, lengkap dan tepat waktu.

Pimpinan dapat dengan mudah memantau dari ruangan kerjanya

R1 : “...Terima kasih karena sistem yang anda buat telah memudahkan pekerjaan teman-teman. Saya juga dengan mudah mendapatkan informasi alat kesehatan....".

R2 : "....Sistem ini telah memudahkan saya untuk memantau kondisi alat kesehatan, sebelum adanya sistem ini saya hanya menunggu laporan dari Pembantu Pengurus Barang. Sistem yang baru ini dapat memberikan informasi yang akurat dan lengkap sesuai dengan yang saya butuhkan. Sekarang ini pembuatan laporan bisa tepat waktu...”.

R4 : “...Kini saya dengan mudah melakukan pemantauan kondisi alat kesehatan, kalibrasi, peminjaman maupun usulan perbaikan alat. Sistem yang baru ini dapat menyajikan informasi yang akurat dan lengkap sesuai dengan yang saya butuhkan....".

6. Pengguna dapat membuat laporan yang sesuai, akurat, lengkap dan tepat waktu dengan cara yang mudah dan cepat.

Dapat membuat laporan yang sesuai, akurat, lengkap dan tepat waktu dengan cara yang mudah dan cepat

R2 : “....Dengan adanya sistem yang baru ini informasi menjadi lebih akurat dan lengkap sesuai dengan kebutuhan. Pembuatan laporan juga menjadi lebih mudah...".

R4 : "....Data alat kesehatan sekarang ini lebih akurat dan lebih lengkap. Ini sangat membantu saya. Saya biasanya membuat laporan menggunakan Excel dan harus melakukan rekap data secara manul. Tapi sekarang dengan adanya sistem yang baru saya jadi sangat terbantu. Untuk membuat laporan alat kesehatan sekarang ini menjadi mudah dan cepat sehingga saya tidak terlambat lagi dalam pembuatan laporan....". 
Setelah diimplemntasikan sistem informasi pemantauan alat kesehatan, dilakukan analisis kualitas informasi sebelum dan sesudah dilakukan pengembangan sistem.

Analisis Kualitas Informasi pada Vaiabel Ketersediaan Hasil perhitungan nilai rata-rata kualitas informasi pada variabel ketersediaan sebelum sistem dikembangkan sebesar 2,06 dan sesudah dikembangkan sebesar 4,32. Nilai rata-rata sebelum dan sesudah sistem dikembangkan terdapat kenaikan sebesar 2,26. Peningkatan ketersediaan informasi pada sistem yang dikembangkan juga dikemukakan oleh responden.

R2 : "Sistem yang baru ini menyediakan informasi yang saya butuhkan untuk melakukan pemantauan alat kesehatan....".

R3 : "Kalo dulu saya sulit mendapatkan informasi kondisi alat di semua ruangan pelayanan, tapi kini sistem yang baru telah menyediakan informasi yang saya butuhkan....."

R4 :"...Saya sangat terbantu dengan dikembangkan sistem ini, informasi yang saya butuhkan sudah tersedia di sistem ini...".

Analisis Kualitas Informasi pada Vaiabel Kelengkapan

Hasil perhitungan nilai rata-rata kualitas informasi pada variabel kelengkapan sebelum sistem dikembangkan sebesar 2,05 dan sesudah dikembangkan sebesar 4,23. Nilai rata-rata sebelum dan sesudah sistem dikembangkan terdapat kenaikan sebesar 2,18. Peningkatan kelengkapan informasi pada sistem yang dikembangkan sesuai dengan yang dikemukakan oleh responden berikut.

Kelengkapan Informasi

R2: “...Sistem yang baru memang menyediakan informasi yang lebih lengkap, seperti adanya informasi peminjaman, pemeliharaan rutin, laporan kalibrasi dan rekapitulasi alat..."

R3 : “...Dengan adanya pengembangan sistem ini saya menjadi lebih mudah melakukan pemantauan. Sistem ini telah menyediakan informasi yang cukup lengkap untuk memantau alat kesehatan di semua ruangan pelayanan...".

Analisis Kualitas Informasi pada Vaiabel Kesesuaian

Hasil perhitungan nilai rata-rata kualitas informasi pada variabel kesesuaian sebelum sistem dikembangkan sebesar 2,12 dan sesudah dikembangkan sebesar 4,36. Nilai rata-rata sebelum dan sesudah sistem dikembangkan terdapat kenaikan sebesar 2,22. Peningkatan kesesuaian informasi pada sistem yang dikembangkan juga dikemukakan oleh responden seperti berikut ini.

\section{Ketersediaan informasi}

R1 :“....Sistem yang anda bangun telah membantu kami dalam pemantauan alat. Sistem ini telah menyediakan informasi yang dibutuhkan...".

R2 :“.... Sistem yang baru ini telah menyediakan informasi yang saya butuhkan dalam melakukan pemantauan alat yang ada di ruangan pelayanan...".

R4 :“....Sebelumnya saya mengalami kesulitan untuk mendapatkan informasi yang sesuai. Tetapi dengan adanya pengembangan sistem ini, informasi yang ada pada sistem sudah sesuai dengan yang saya butuhkan...".

Analisis Kualitas Informasi pada Vaiabel Keakuratan

Hasil perhitungan nilai rata-rata kualitas informasi pada variabel keakuratan sebelum sistem dikembangkan sebesar 2,13 dan sesudah dikembangkan sebesar 4,40. Nilai rata-rata sebelum dan sesudah sistem dikembangkan terdapat kenaikan sebesar 2,27. Peningkatan keakuratan informasi sesudah 
pengembangan sistem juga dikemukakan oleh responden berikut.

\section{Keakuratan Informasi}

R2 : “...Semula saya sering mendapatkan infomasi yang tidak akurat. Tapi kini dengan adanya sistem ini saya dengan mudah mendapatkan informasi yang akurat....".

R3 : “...Sistem yang baru ini sangat membantu saya. Kini data dan informasi yang akurat dapat dengan mudah peroleh. Semula saya harus mendatangi ruangan pelayanan, kini informasi yang akurat cukup saya lihat di komputer saya...".

Analisis Kualitas Informasi pada Vaiabel Ketepatan Waktu

Hasil perhitungan nilai rata-rata kualitas informasi pada variabel ketepatan waktu sebelum sistem dikembangkan sebesar 2,15 dan sesudah dikembangkan sebesar 4,33. Nilai rata-rata sebelum dan sesudah sistem dikembangkan terdapat kenaikan sebesar 2,22. Peningkatan ini sejalan dengan pernyataan yang disampaikan oleh responden berikut.

\section{Ketepatan waktu informasi}

R2 : “....Semula laporan sering terlambat dan tidak tepat waktu. Tapi dengan menggunakan aplikasi sistem yang baru usulan dan pembuatan laporan selalu tepat waktu.

R3 : “....Kini usulan perbaikan dan pelaporan sudah bisa tepat waktu. Karena sudah tersedia di aplikasi sistem yang baru yang dapat dilakukan dari ruangan pelayanan

R4 : "....Sebelum ada sistem ini saya sering membuat laporan tidak tepat waktu. Tapi sekarang setelah adanya sistem ini saya dengan mudah membuat laporan dan tidak telat lagi".

\section{Kesimpulan}

Berdasarkan hasil evaluasi kualitas informasi setelah empat pekan diimplementasikan sistem informasi pemantauan alat kesehatan terbukti telah mampu mengatasi masalah ketersediaan, kesesuaian, kelengkapan, keakuratan dan ketepatan waktu informasi. Hal ini menjadi bahan evaluasi bagi BKIM Provinsi Jawa Tengah. Peningkatan kualitas informasi yang signifikan terlihat dari nilai rata-rata tertimbang variabel yang diteliti secara keseluruhan meningkat, dengan ratarata sebelum pengembangan sistem adalah sebesar 37,87 dan setelah pengembangan sistem 78,90 dengan selisih 41,03. Hal ini membuktikan adanya peningkatan yang signifikan tentang ketersediaan, kesesuaian, kelengkapan, keakuratan dan ketepatan waktu informasi sebelum dan sesudah pengembangan sistem. Sistem informasi pemantauan alat kesehatan menyediakan informasi yang lengkap, akurat dan tepat waktu sesuai dengan kebutuhan untuk melakukan pemantauan alat kesehatan sesuai dengan tingkatan manajemen untuk mendukung penjaminan mutu pelayanan kesehatan di BKIM Provinsi Jawa Tengah.
Disarankan kepada BKIM Provinsi Jawa Tengah perlu adanya dukungan dan komitmen dari BKIM Provinsi Jawa Tengah dalam mengimplementasikan sistem informasi pemantauan alat kesehatan sebagai sumber informasi dalam pemantauan alat kesehatan untuk mendukung penjaminan mutu pelayanan kesehatan di BKIM Provinsi Jawa Tengah. Perlu adanya tenaga teknis yang mampu melakukan pemantauan kondisi fisik alat kesehatan dan kalibrasi secara berperiodik, sehingga alat kesehatan di BKIM Provinsi Jawa Tengah benar-benar dalam pantauannya. Sistem informasi pemantauan alat kesehatan dapat dikembangkan dengan mengintegrasikan sistem ini dengan sistem aset yang memang sudah lebih dahulu diimplementasikan BKIM Provinsi Jawa Tengah

\section{Daftar Pustaka}

1. Departemen Kesehatan RI. Pedoman Kerja Balai Kesehatan Mata Masyarakat. Jakarta: Ditjen Bina Kesehatan Masyarakat: 1998. 
2. BKIM Provinsi Jawa Tengah. Profil BKIM. Semarang: 2014.

3. Departemen Kesehatan RI Direktorat Jenderal Pelayanan Medik. Pedoman Pengujian dan Kalibrasi Alat KesehatanInmproving Calibration System of Medical Equipment in the Hospital Product 3 Second Stage Activities. Jakarta: 2001.

4. Departemen Kesehatan RI. Peraturan Menteri Kesehatan Republik Indonesia Nomor : 1184/Menkes/Per/X/2004 Tentang Pengamanan Alat Kesehatan dan Perbekalan Kesehatan Rumah Tangga. 2004.

5. Sugiharto, Mugeni. Pengembangan Metode Skreening USG di Puskesmas Poned Kabupaten Jombang Provinsi Jawa Timur (Studi Kasus Hta). Buletin Penelitian Sistem Kesehatan. Oktober 2011; Vol. 14; No. 4.

6. Janahar. Penelitian Sistem Monitoring Efek Pengamanan Alat Kesehatan. Jakarta: Depkes RI; 1991.

7. Kuning Atmadjaya, I Nengah. Alat Kesehatan RSUP Sanglah. Denpasar: Tribun Bali; 2015. 